\title{
Más allá de la crisis. Horizontes desde una perspectiva descolonial
}

Recibido: $28 / 02 / 2019$

Aprobado:23/05/2018

\author{
CÉSAR GERMANÁ \\ Universidad Nacional Mayor de San Marcos \\ cagermana@yahoo.com
}

\section{RESUMEN}

En este artículo se argumenta sobre las reflexiones de Aníbal Quijano que han estado orientadas a la elaboración de una nueva manera de plantear los problemas de América Latina. Desde las diversas cuestiones que se busca explorar a lo largo de su extensa producción teórica, se examina tres debates medulares que han estado en el centro de sus preocupaciones y que resultan fundamentales para dar cuenta de las formas de organización y de las posibilidades de transformación del orden social actual. En primer lugar, la noción de patrón de poder; en segundo lugar, la naturaleza de la crisis del patrón de poder colonial/moderno; y, en tercer lugar, las tendencias hacia la descolonialidad del poder y las opciones históricas del futuro.

Palabras clave: Aníbal Quijano, patrón de poder colonial/moderno, crisis raigal, descolonialidad del poder.

\section{Beyond the crisis. Horizons from a decolonial perspective}

\begin{abstract}
This article argues on the reflections of A nibal Q uijano, which h ave b een focused on conceiving a new approach to understand the problems of Latin America. Among the different subjects to be explored within his vast theoretical production, we will examine three core ideas that remain central to his concerns and that are fundamental to explain the forms of organization and the possibilities of transformation of the current social order. First, the notion of pattern of power; secondly, the nature of the crisis of the colonial/modern pattern of power; and third, the tendencies towards decoloniality of power and the future historical options.
\end{abstract}

Keywords: Anibal Quijano, colonial/modern pattern of power, deep-rooted crisis, decoloniality of power. 
níbal Quijano es un pensador respetado y querido en América Latina.
Su pensamiento creativo y riguroso ha posibilitado ampliar nuestro
conocimiento sobre el mundo en el que vivimos. Ha tenido la osadía
intelectual necesaria para ir en contra del hegemónico pensamiento social eurocéntrico. Desde la periferia del patrón de poder colonial/moderno, ha planteado las categorías más apropiadas para ser capaces de asumir una mirada propia sobre la realidad histórico-social. Para comprometerse con este desafío, "es indispensable liberar nuestra retina histórica de la prisión eurocentrista y re-conocer nuestra experiencia histórica" (Quijano, 2007, p. 353). Esa ha sido la tarea que se propuso y llevó adelante en su extensa obra, teórica y práctica.

Desde sus primeros trabajos, las reflexiones de Aníbal Quijano tienen como punto de partida la constatación de la profunda crisis del pensamiento científico-social; crisis que se hizo evidente hacia fines de la década de 1960 e inicios de la década de 1970. Consideraba que los principios sobre los que se construyeron históricamente las ciencias sociales, en Europa en el siglo XIX, constituían el principal obstáculo intelectual para comprender el mundo actual. A esta situación la denominó “crisis de paradigmas” (Quijano, 1990a). En el caso de América Latina esta crisis tiene características específicas y dio lugar a una "crisis de problemática". Esta crisis se encuentra vinculada, en lo fundamental, con el hecho de que las preguntas que se le hacen a la realidad histórico-social latinoamericana no son ya intelectual y políticamente significativas. Para Quijano (1990a, pp. 13-14), "ya no ayudan satisfactoriamente a describir el significado de lo que percibimos y mucho menos a descubrir y hacer inteligibles las zonas no inmediatamente perceptibles de la realidad'. Las cuestiones que habían dominado el debate, después de la Segunda Guerra Mundial en la región, las habían impuesto la perspectiva del dualismo estructural — tanto en su versión de la teoría de la modernización, basada en el estructural-funcionalismo, como en la del "materialismo histórico", la versión más influyente del marxismo positivista - y la del empirismo (Quijano, 1990b). Esa problemática, a todas luces, era insuficiente para comprender las profundas transformaciones que se estaban produciendo en América Latina y en el mundo, por lo era necesario establecer nuevas cuestiones en el debate, es decir, "la reconstitución de una problemática latinoamericana" (Quijano, 1990 b, p. 18). Esta alternativa al pensamiento social eurocéntrico se cimentaría sobre nuevos principios epistemológicos de un conocimiento social emergente. 
Precisamente las reflexiones de Quijano han estado orientadas a la elaboración de una nueva manera de plantear los problemas de América Latina. Desde las diversas cuestiones que buscó explorar a lo largo de su extensa producción teórica, aquí se examinarán tres debates medulares que han estado en el centro de sus preocupaciones y que resultan fundamentales para dar cuenta de las formas de organización y de las posibilidades de transformación del orden social actual. En primer lugar, la noción de patrón de poder; en segundo lugar, la naturaleza de la crisis del patrón de poder colonial/moderno; y, en tercer lugar, las tendencias hacia la descolonialidad del poder y las opciones históricas del futuro.

\section{El patrón de poder colonial/moderno/eurocentrado}

El punto de partida necesario para comprender los análisis que propone Quijano es un problema ontológico: la cuestión de cómo se produce y se reproduce la existencia social de los seres humanos. En su propuesta, lo específico de la existencia social está dado por la trama cambiante de relaciones sociales que los seres humanos establecen entre sí. Estas relaciones sociales son el resultado de la práctica social, en la medida que el ser humano, como ser histórico-natural, puede decidir su propia existencia. En la base de esta visión se encuentra el cuestionamiento al radical dualismo cartesiano que separa sociedad y naturaleza. Quijano (2013, pp. 22-23) lo explica señalando el surgimiento de las formas modernas de conocimiento:

Pero ese nuevo modo de conocimiento, que se llamará después la ciencia y que al comienzo parece algo también propiamente europeo, tiene un fundamento que es también una paradoja en sí misma, el radical dualismo cartesiano, que separa razón y naturaleza, porque la razón es un don divino y tiene carácter divino, el cuerpo y el resto son naturaleza y no tiene carácter divino. Ese dualismo cartesiano prolonga y desarrolla, aunque la seculariza como filosofía, la teología cristiana medieval que separa alma y cuerpo. Y eso parece un gran adelanto, de hecho esto se convierte en la base misma de la llamada racionalidad moderna. Este mecanismo intelectual, desde nuestra perspectiva actual, de origen místico y de carácter metafísico, pasa a ser el fundamento mismo de la "racionalidad científica" y "moderna".

En este sentido, la existencia social no se constituye como producto de la acción subjetiva de los seres humanos ni es el resultado de las estructuras 
materiales, sino es la consecuencia — como señaló Marx — de la “actividad humana sensorial, como práctica.

$\mathrm{Su}$ concepción de la historia - como un proceso resultado de la acción transformadora de los seres humanos- necesariamente lo llevó a desechar una estrategia de análisis donde los fenómenos puedan ser considerados como objetos, llámense estos economía, instituciones políticas o ideología. En su perspectiva, esos hechos sociales cosificados se disuelven en las relaciones sociales que los determinan. Lo que aparecía rígido y opaco cobra vida y los "hechos sociales" se muestran como relaciones entre seres humanos. A estas relaciones sociales — y no a sus apariencias — apunta su investigación; quiere reconstruir esa trama compleja y abigarrada que es la vida humana más allá de sus manifestaciones objetivadas.

La praxis social constituye la base sobre la que se establecen las relaciones sociales - los vínculos que establecen los seres humanos entre sí- y se producen y reproducen a lo largo de la historia. Quijano (2000a, p. 345) distingue cinco ámbitos que se puede analíticamente distinguir en la existencia social:

[...] (1) el trabajo y sus productos; (2) en dependencia de lo anterior, la "naturaleza" y sus recursos de producción; (3) el sexo, sus productos y la reproducción de la especie; (4) la subjetividad y sus productos, materiales e intersubjetivos, incluido el conocimiento; (5) la autoridad y sus instrumentos, de coerción en particular, para asegurar la reproducción de ese patrón de relaciones sociales y regular sus cambios.

Desde su perspectiva de análisis, estos diferentes ámbitos de la existencia social, si bien constituyen esferas heterogéneas de relaciones sociales, están profundamente articulados entre sí, de tal manera que unos definen a los otros y no se les puede analizar simplificando la realidad social sino examinándolos en su complejidad como una totalidad. El eje articulador de ese heterogéneo mundo de relaciones sociales es, para Quijano, el poder. La cuestión del poder es el eje central que atraviesa su pensamiento. "El poder — escribe - sigue siendo el patrón más universal de estructuración de la sociedad. Toda crítica de toda sociedad es aún, necesariamente, ante todo una crítica del poder vigente" (Quijano, 1990a, p. 22). El poder no lo considera como una cosa, sino como un entramado de relaciones sociales de dominación y explotación. Pero, además, señala que no existe un ejercicio absoluto del poder: los dominados luchan para modificar el control de esas relaciones de dominación en cada uno 
de los ámbitos de la existencia social. En este sentido, las relaciones sociales se estructuran en un patrón de dominación/explotación y en un patrón de conflicto. "Porque es el poder, ergo las luchas de poder y sus cambiantes resultados, aquello que articula formas heterogéneas de existencia social, producidas en tiempos históricos distintos y en espacios distantes, aquello que las junta y las estructura en un mismo mundo, en una sociedad concreta, finalmente, en patrones de poder históricamente específicos y determinados" (Quijano, 2007, p. 352).

Para Quijano, el patrón de poder constituye una estructura básica, una matriz que permite articular el conjunto de las relaciones sociales que atraviesan y cruzan todos los ámbitos de la existencia social estableciendo una totalidad histórica compleja. Para delimitarla deslinda tanto con las visiones eurocéntricas orgánicas y sistémicas de la totalidad como con el enfoque empirista atomístico y de las corrientes posmodernas que niegan la existencia de una totalidad histórico social, en la medida que estas buscan impugnar la existencia del poder social. Considera que es aparente la oposición entre ambas perspectivas, pues una y otra comparten la misma idea eurocéntrica de la totalidad:

En esa confrontación señala entre las ideas orgánicas y sistémicas de totalidad, de un lado, y la negación de toda idea de totalidad, del otro, pareciera pues tratarse de opciones muy contrapuestas, incluso referidas a perspectivas epistémicas no conciliables. Ambas tienen, sin embargo, un común linaje eurocéntrico: para ambas posiciones el paradigma eurocéntrico de totalidad es el único pensable (Quijano, 2000a, p. 354).

En la propuesta de Quijano, un patrón de poder se presenta como una totalidad compleja en la medida que está constituida por los diferentes ámbitos de la existencia social, que a la vez son heterogéneos y discontinuos, donde unos definen a los otros y se redefinen entre sí. Además, el patrón de poder constituye una realidad histórica pues tiene un inicio, ya que surge en un determinado momento, tiene un desarrollo y llega a un punto de bifurcación que marca su fin.

Quijano se interesó en la exploración de las características, desarrollo y crisis de un específico patrón de poder: el patrón de poder colonial/moderno/ eurocentrado.

Para Quijano este sui generis patrón de poder surgió en 1492. Propone que con la conquista ibérica de lo que posteriormente se va a llamar América se constituyó un nuevo patrón de poder que era efectivamente mundial y que 
duraría más de cinco siglos. Este patrón de poder mundial tiene como fundamento la colonialidad, ${ }^{1}$ porque no solo se trató de una colonización económico-política, sino que estuvo atravesado por la idea de "raza", de acuerdo con la cual se establece la dominación y la clasificación social mundial de la población. Las relaciones de poder que se establecen entre lo europeo y lo no europeo sobre la base de la "raza", presentada como diferencias biológicas entre los seres humanos que hacen a unos superiores - los conquistadores - y a otros inferiores - los colonizados — . La colonialidad ha producido la transmutación de las condiciones de dominación —un hecho social— en jerarquías biológicas; esto es, en relaciones raciales. Lo que fue producto de la dominación colonial se ha mantenido como colonialidad cuando las áreas colonizadas logran su autonomía jurídico-política; así se fueron reproduciendo las relaciones "raciales" de superioridad/inferioridad como la base sobre la que se sostienen las actuales estructuras del patrón de poder mundial. En el mundo de las relaciones intersubjetivas y en las prácticas sociales, la colonialidad implica, como señala Quijano (1993, p. 169), que "los no-europeos tienen una estructura biológica no solamente diferente de la de los europeos; sino, sobre todo, perteneciente a un tipo o a un nivel 'inferior"'.

Con la colonialidad del poder, las relaciones de explotación, dominación y conflicto se "racializan"; esto es, las relaciones de poder se naturalizan en la medida en que los dominantes se autodefinen como superiores y consideran inferiores a los dominados. Más aún, y este es el efecto más perverso de esas relaciones coloniales de dominación, los propios dominados se convierten en cómplices de su propia dominación al aceptar como legítima la supuesta superioridad biológica de los conquistadores. La colonialidad del poder, en este sentido, se convertirá en la forma de dominación más eficiente tanto en los aspectos materiales como intersubjetivos de la existencia social.

La otra cara de este patrón mundial de poder actualmente vigente es la modernidad que se presenta como la cara ilustrada y es considerada como el proceso de creciente racionalización de los diferentes órdenes de la vida social. Quijano la considera como el vasto conjunto de cambios que se dieron en la totalidad del mundo bajo la hegemonía europea, a partir del siglo XVI, y que significó la creciente racionalización de la existencia social, en el sentido

1 Aníbal Quijano introdujo el concepto de colonialidad del poder en Quijano (1991). Posteriormente lo desarrolló en varios otros textos: Quijano y Wallerstein (1992), Quijano (1993, 2000a, 2000b, 2000c, 2001, 2003, 2004, 2007 y 2009). Para un debate fructífero sobre este concepto, véase los siguientes textos: Mignolo (2003) y Escobar (2003). 
de lo que Max Weber denominaba "racionalidad formal" o Max Horkheimer "racionalidad instrumental". Esto es, se trata de formas de relaciones sociales donde la acción está guiada por el cálculo de los medios; siendo racional la conducta exitosa, aquella que ha utilizado los medios más adecuados para alcanzar un determinado fin. Esta forma de racionalidad, según Quijano (1988, p. 17), se impuso en la "razón burguesa" frente a la "racionalidad histórica" que implicaba "una promesa de existencia social racional, en tanto que promesa de libertad, de equidad, de solidaridad, de mejoramiento continuo de las condiciones materiales de esa existencia social, no de cualquier otra". En ese sentido, expresaría lo nuevo y lo más avanzado de la especie; y donde la historia humana sería considerada como una trayectoria cuyo destino final estaría dado por la Europa Occidental que surge en el siglo XVI; proceso que constituiría el fin de la historia.

De esta manera, como lo dijo Quijano (1991) ${ }^{2}$ en una entrevista: "La modernidad, el capitalismo y América Latina nacen el mismo día”. Esta idea se precisa en el siguiente texto:

Con la constitución de América (Latina), en el mismo momento y en el mismo movimiento históricos, el emergente poder capitalista se hace mundial, sus centros hegemónicos se localizan en las zonas situadas sobre el Atlántico — que después se identificarán como Europa- y como ejes centrales de su nuevo patrón de dominación se establecen también la colonialidad y la modernidad. En breve, con América (Latina) el capitalismo se hace mundial, eurocentrado y la colonialidad y la modernidad se instalan asociadas como los ejes constitutivos de su específico patrón de poder, hasta hoy (Quijano, 2000a, p. 342).

Considerando a la colonialidad como el eje central de la estructura del patrón de poder mundial, Quijano examina cuatro componentes que le son constitutivos.

Primero, el capitalismo como el patrón universal de explotación social de todas las formas históricamente conocidas de control del trabajo, distribuido mundialmente en torno a la colonialidad del poder, donde el capital las articula para producir mercancías para el mercado mundial.

Segundo, el Estado como forma universal de control de la autoridad colectiva, en donde el Estado-nación es su variante predominante.

2 Es muy significativo tener en cuenta la continuidad de esta tesis con la fecunda intuición de José Carlos Mariátegui planteada en una respuesta a una encuesta de la revista Variedades: "El descubrimiento de América es el principio de la modernidad: la más grande y fructuosa de las cruzadas. Todo el pensamiento de la modernidad está influido por este acontecimiento" (Mariátegui, 1994, p. 1397). 
Los Estados-nación del centro se constituyeron teniendo como contrapartida los Estados-coloniales, primero y los Estados-nacional dependientes después. Como parte de esa relación, los procesos de ciudadanización, de representación desigual pero real de los diversos sectores sociales, la retribución en servicios públicos de la producción y de la tributación de los trabajadores (llamado Welfare State), no ha dejado de ser, en definitiva, privilegio del centro, porque su costo se paga en muy amplia medida por la explotación del trabajo de la periferia colonial en condiciones no democráticas y no nacionales, esto es como sobre-explotación (Quijano, 2000a, p. 375).

Tercero, la colonialidad de las relaciones entre los géneros: "En todo el mundo colonial, las normas y los patrones formal-ideales de comportamiento sexual de los géneros y en consecuencia los patrones de organización familiar de los 'europeos' fueron directamente fundados en la clasificación 'racial'" (Quijano, 2000a, p. 377).

Cuarto, el eurocentrismo impuesto en el entero patrón de poder colonial/ moderno como la única forma legítima de racionalidad, en particular la forma de producir conocimientos. Es la geocultura del patrón de poder colonial/moderno que ha buscado garantizar su permanente reproducción. Esta estructura del saber desde sus orígenes excluyó tanto a las poblaciones que fueron colonizadas consideradas humanamente inferiores como a sus maneras de conocer y a sus saberes en virtud de la hegemonía de la epistemología eurocéntrica.

Para Quijano, el eurocentrismo es la estructura de saber que ha buscado garantizar el mantenimiento del patrón de poder colonial/moderno. Corresponde a una manera específica de percibir y ordenar el mundo natural y social. Es la expresión, en el mundo de las relaciones intersubjetivas, de la colonialidad del poder. Es una perspectiva que se caracteriza por la hegemonía europea en la manera de producir conocimientos. La especifica teniendo en cuenta los siguientes rasgos:

- atribuye al europeo la calidad de medida y de referencia privilegiadas de la experiencia de toda especie;

- lleva a mirar todo desde esa posición;

- tiende a organizar la percepción del mundo según las categorías de procedencia europea, consideradas como las únicas legítimamente válidas;

- condiciona, de ese modo, al dominado a mirarse con los ojos del dominador (Quijano (1992, p. 74).

Para los pueblos que fueron colonizados, el eurocentrismo significó la subalternización de sus visiones del mundo. Entre sus efectos se encuentran: 
- "Las poblaciones colonizadas fueron reducidas a ser campesinas e iletradas".

- "Serían impedidas de objetivar sus propias imágenes, símbolos y experiencias subjetivas, de modo autónomo, es decir con sus propios patrones de expresión visual y plástica".

- Solo podían expresarse "única y exclusivamente con y por medio de los patrones de expresión visual y plástica de los dominadores".

- "Fueron compelidas a abandonar bajo represión las prácticas de relación con lo sagrado propio o realizarlas solo de modo clandestino con todas las distorsiones implicadas".

- "Fueron llevadas a admitir. O simular admitir frente a los dominadores, la condición deshonrosa de su propio imaginario y de su propio previo universo de subjetividad" (Quijano, 2001, pp. 121-122).

Por lo señalado se puede considerar que la noción de colonialidad del poder constituyó la herramienta heurística central que utilizó Quijano para explorar el modo de organización y la dinámica del sistema histórico colonial/moderno que se estableció en 1492 y que en la actualidad ha ingresado a un "nuevo periodo histórico: la crisis raigal de la colonialidad global del poder" (Quijano, 2014, p. 852).

\section{La naturaleza de la crisis raigal del patrón de poder colonial/ moderno}

La crisis significa, fundamentalmente, reorganización y transición. El periodo que estamos viviendo es el de la reorganización de un sistema histórico que no puede seguir reproduciéndose porque los problemas estructurales que se le plantean no se resuelven y se ha abierto el camino para el surgimiento de otro patrón de poder. La estructura de poder que se constituyó hace quinientos años se está desmoronando y otra, que todavía no conocemos, está surgiendo delante de nosotros. Nos hallamos en una época donde el patrón de poder colonial/moderno está llegando a su fin y está entrando en un periodo de transición hacia un nuevo patrón de poder. La crisis abarca todos los ámbitos y niveles, con diferentes velocidades y contradicciones, de la colonialidad/modernidad/eurocentrada:

No es, por consecuencia, solamente el capital, ni solamente el capitalismo lo que está en estos momentos en crisis, es todo un patrón de poder, y ese patrón de poder ha puesto en juego, además, la crisis de eso llamado "naturaleza" en nuestro planeta. Se trata de un poder muy específico, cuyas perspectivas actuales y cuyos procesos inmediatamente futuros, como podemos vislumbrar ahora sin 
dificultad, corren de manera creciente, a menos que tengamos alguna manera de detenerlo o de controlarlo, no solamente a destrucción de nuestra casa común, el planeta, sino a nuestra propia destrucción, no solamente por la crisis planetaria, porque nos estamos matando entre nosotros, cada vez más en favor y en función de lo que necesita hoy ese patrón de poder (Quijano, 2013, pp. 36-37).

En esta perspectiva, se puede señalar al menos los tres aspectos más significativos de la crisis raigal del patrón de poder colonial/moderno.

En primer lugar, la crisis del capitalismo y su modelo de desarrollo debido a su incapacidad para resolver los problemas que genera la acumulación incesante de capital, tanto por la creciente miseria de las masas explotadas como por la agudización de la crisis climática, el "vector ecológico".

Ya desde 1973, Quijano percibía los aspectos medulares de la "naturaleza actual de la crisis del capitalismo". Apoyándose en los análisis de Marx, en los Elementos fundamentales para la crítica de la economía política 18571858 , identificaba el núcleo del derrumbe de toda la economía del valor por la caída de la tasa de ganancia del capital a consecuencia de su propio proceso de sobreacumulación, proceso que empieza desde inicios de la década de 1970. Considera que el desarrollo de las fuerzas productivas, basadas en el desarrollo científico y tecnológico, incrementan la calidad y cantidad de los medios técnicos de producción reduciendo el papel del trabajo vivo; la máquina y no el trabajo es la fuerza valorizadora. Por lo tanto, el tiempo de trabajo cesa de ser el principio determinante de las relaciones de producción capitalista. Este proceso Quijano lo explica en el siguiente texto:

A partir del momento en que el proceso de producción deja de ser un intercambio entre el trabajo vivo y el trabajo acumulado u objetivado, puesto que los medios técnicos han asumido el papel de medios de producción y de agentes de producción, al mismo tiempo, y la fuerza valorizante del obrero ha devenido infinitamente pequeña, la producción no consiste más en la creación de valor sino, básicamente, en la transferencia de valor. Los medios técnicos, nuevos agentes de producción, no crean un nuevo valor. Solo pueden transferir al producto, parte del trabajo acumulado o de valor que condensan. En este momento, por lo tanto, deja de producirse plusvalía (Quijano, 1975, p. 150).

Quijano concluye que si la ley del valor cesa de actuar en la producción, el sistema capitalista deja de existir. Y como señalaba Marx (1972, t. II, p. 222) "el capital trabaja, así, en favor de su propia disolución, como forma dominante de la producción”. Con el advenimiento de la llamada cuarta revolución 
industrial - la convergencia de tecnologías digitales, físicas y biológicas-, se puede comprender cabalmente que el capital en los sectores tecnológicamente más avanzados se ha desarrollado completamente de tal modo que el trabajo vivo se reduce drásticamente. "Si ello es así, el capitalismo en tanto que sistema de producción y acumulación de plusvalía y fundado en la ley del valor, ha llegado al límite de sus posibilidades históricas de existencia y se abre él mismo a su disolución" (Quijano, 1975, p. 150).

Estos cambios en el desarrollo de la economía mundial son tan profundos y drásticos que ha dado lugar a la creciente financiarización estructural del capitalismo y a una vasta reorganización del mundo del trabajo.

En cuanto a lo primero, Quijano señalaba que la búsqueda de acumulación incesante de capital lleva a la ampliación de la acumulación especulativa de capital: "Y conforme esa tendencia avanza, paralelamente se van ampliando los circuitos de acumulación ficticia de capital, esto es no productiva, ni vinculada a la producción ni aun indirectamente, desarrollando mecanismos ficticios de capital" (Quijano, 1975, p. 160). De esta manera, se "fue configurando un nuevo capital industrial/financiero, que pronto tuvo una relativamente rápida expansión mundial” (Quijano, 2014, p. 850)

En cuanto a lo segundo, en el ensayo "El trabajo al final del siglo XX", Quijano (2014) señala tres tendencias fundamentales: primero, la disminución radical, hasta la pérdida casi completa del trabajo asalariado en los sectores tecnológicamente más avanzados de la economía capitalista; segundo, la expansión del desempleo estructural a nivel mundial, en la medida que dejaba de ser coyuntural o cíclico; y, tercero, como contrapartida de la desocupación estructural, la re-expansión del trabajo no asalariado (la pequeña producción mercantil simple, la servidumbre, la esclavitud, la reciprocidad).

Para Quijano, otro indicador de la crisis raigal del patrón de poder colonial/moderno está dado por el "vector climático":

Lo que esto implica actualmente no es solo la creciente exacerbación de su inherente conflictividad, lo que todos podemos observar en todo el mundo, sino también, al mismo tiempo, la agudización de una crisis climática planetaria que, según la mayoría de la comunidad científica mundial, habría sido producida por la sobre-explotación y la contaminación de los recursos del planeta, al servicio de las cada vez más desorbitadas exigencias de bienestar material artificial y de lucro, en particular de los controladores de este patrón de poder. Es decir, como resultado de la operación del propio patrón de poder globalmente dominante. Desde esa perspectiva, la crisis climática planetaria actual tiene que ser con- 
siderada como una dimensión de la propia crisis de la colonialidad del poder (Quijano, 2013, p. 18).

Así, una de las características más significativas del capitalismo ha sido considerar a la naturaleza como un objeto que puede ser explotado indefinidamente. La crisis ecológica producto del calentamiento global del clima es el resultado de la exacerbación del carácter expoliador de la naturaleza del capitalismo industrial/financiero:

Y, sobre esa base, el capitalismo colonial/global practica una conducta cada vez más feroz y predatoria, que termina poniendo en riesgo no solamente la sobrevivencia de la especie entera en el planeta, sino la continuidad y la reproducción de las condiciones de vida, de toda vida, en la Tierra. Bajo su imposición, hoy estamos matándonos entre nosotros y destruyendo nuestro común hogar (Quijano, 2014, p. 855).

En segundo lugar, la crisis del estado-nación como consecuencia tanto de la creciente pérdida de soberanía como por una paulatina limitación a los derechos democráticos, especialmente sociales, de los ciudadanos. Para Quijano, la ciudadanía y la democracia liberal que han sido constitutivas de los Estados-nación de los países centrales y limitadamente impuestos en los periféricos no es compatible con la re-privatización del poder a escala mundial que ha configurado un "bloque imperial mundial", 3 que ha llevado a "una re-concentración mundial del control de la autoridad pública, a escala global" (Quijano, 2001). Las profundas transformaciones que se están produciendo en el patrón de poder colonial/moderno pone en cuestión los fundamentos mismos del Estado-nación moderno: "En los actuales procesos de cambio histórico, en la contrarrevolución mundial nombrada como globalización, las

3 Quijano lo conceptualiza de la siguiente manera: "Nadie podría hoy negar que unos pocos de los modernos Estados-nación —el Grupo de los 7, ahora de 8 con la tardía y subordinada incorporación de Rusia-más fuertes, varios de ellos sedes centrales de los modernos imperios coloniales y todos ellos del imperialismo capitalista durante el siglo XX, forman ahora en su conjunto un genuino bloque imperial mundial. Primero, porque sus decisiones son impuestas sobre el conjunto de los demás países y sobre los centros neurálgicos de las relaciones económicas, políticas y culturales del mundo. Segundo, porque lo hacen sin haber sido elegidos, o siquiera designados, por los demás Estados del mundo, de los cuales no son por lo tanto representantes, ni, en consecuencia, tienen que consultarlos para sus decisiones. Son virtualmente una autoridad pública mundial, aunque no un efectivo Estado mundial.

Ese bloque imperial mundial no está constituido solo por los Estados-nación mundialmente hegemónicos. Se trata, más bien, de la configuración de una suerte de trama institucional imperial formada por tales Estados-nación, las entidades intergubernamentales de control y ejercicio de la violencia, como la OTAN, las entidades intergubernamentales y privadas de control del flujo mundial de capital, financiero en especial (Fondo Monetario Internacional, Banco Mundial, Club de París, Banco Interamericano de Desarrollo, entre las principales), y las grandes corporaciones globales. Esa trama institucional constituye ya, de hecho, una suerte de Gobierno mundial invisible" (Quijano, 2001). 
tendencias de reconfiguración del poder implican intereses sociales que no podrían desarrollarse y consolidarse sino a costa de la democracia y de la ciudadanía" (Quijano, 1997, p. 139).

Sin embargo, la tendencia más radical de desnacionalización y des-democratización del Estado se encuentra en los Estados de las sociedades dependientes: "Contener, bloquear, desmantelar, procesos de democratización y ciudadanización en el mundo 'periférico' del capitalismo, parece ser, probablemente es, una necesidad sobre la cual se desarrolla la concentración mundial de control de recursos y de mecanismos de poder público" (Quijano, 1997, p. 151). La crisis del Estado-nación en los países periféricos también se expresa con el surgimiento de Estados plurinacionales comunitarios que implica: autonomía territorial/administrativa, pluralismo radical, representación múltiple, ciudadanía diferencia y derechos de la naturaleza. Además, otro indicador de la crisis del Estado-nación se encuentra en la pérdida de centralidad del Estado para amplios sectores de la población por el surgimiento de otras formas de organización de la vida política basadas en el autogobierno de los ciudadanos, donde los propios interesados deliberan sobre sus asuntos comunes, toman decisiones colectivas y las ejecutan. Se trata de una política no estatal que lleva a la socialización del poder.

En tercer lugar, la crisis del eurocentrismo como perspectiva de conocimiento y de producción de conocimientos que se impuso en el patrón de poder colonial/moderno como la única forma legítima de conocer/saber el mundo. El paradigma eurocéntrico de saber/conocer ha sido cuestionado por la emergencia de movimientos de poblaciones que fueron subalternizadas y que se encuentran en los márgenes de la actual estructura de poder. Estos movimientos están contribuyendo en la tarea de alcanzar nuevos paradigmas epistemológicos no eurocéntricos. En los análisis de Quijano (2009), esta crisis se expresa en los siguientes aspectos:

- La deslegitimación de la idea de raza, sobre todo después de la Segunda Guerra Mundial y la vasta condena de la barbarie cometida por el derrotado régimen nazi. Aunque el racismo se mantiene - e inclusive se incrementa, como está ocurriendo en la actualidad en los países europeos y en Estados Unidos-, ya no se acepta como indiscutible la existencia de razas entre los seres humanos.

- Las contradicciones de la razón instrumental sobre los que se construyó el pensamiento eurocéntrico.

- La emergencia de un nuevo pensamiento social. Las ciencias sociales que se construyeron históricamente sobre la base de un paradigma epistemológico 
eurocéntrico entraron en crisis hacia fines de la década de 1960 como consecuencia de las profundas transformaciones que se estaban produciendo en el patrón de poder colonial/moderno y por los desafíos que desde el propio pensamiento científico se le empezaron a plantear (las ciencias de la complejidad, los estudios feministas, los estudios poscoloniales, la perspectiva de análisis de la colonialidad/descolonialidad del poder).

- La promesa incumplida del horizonte histórico de sentido de la colonialidad/ modernidad constituida por la igualdad social, la libertad y la autonomía individual, veta histórica utópica que no llegó a ser realizada pues "la única forma de que pudieran ser cumplidas, es la desracialización total de la clasificación social de las gentes".

\section{Las tendencias hacia la descolonialidad del poder y las opciones históricas del futuro}

Si la crisis del patrón de poder colonial/moderno significa reorganización y transición, un problema - que es fundamental porque atraviesa e ilumina toda obra de Aníbal Quijano - es el de la exploración de las opciones históricas que remplazarían al moribundo patrón de poder. En sus reflexiones, toma como base dos experiencias clave: la Comunidad Autogestionaria de Villa El Salvador (CUAVES) y el proceso histórico del bien vivir que han desarrollado los pueblos originarios.

La CUAVES se le presenta como la forma institucionalizada de la socialización del poder político ${ }^{4}$ y de la democracia directa, particularmente en el periodo 1979-1983:

La CUAVES fue la primera y hasta aquí la más importante experiencia de democracia directa que lograron establecer los trabajadores del nuevo mundo urbano de América Latina, en el curso de sus luchas contra el poder oligárquico. Inclusive, aunque no mucho después fueron envueltos en la derrota local y mundial de su clase, por un momento ellos asumieron su experiencia, con el nombre de "cuavismo", como la forma propia y el primer tramo de su propia trayectoria del socialismo (Quijano, 1996, p. 7).

La otra experiencia orientada a la descolonialidad del poder está dada por el proceso histórico del bien vivir (sumak qamaña o sumak kawsay) de los pue-

4 "La socialización del poder político consiste en la redistribución del poder político entre los productores organizados, y a través de sus organismos directamente incorporados a su vida cotidiana, de modo que ellos puedan ejercer el control inmediato y directo de ese poder" (Quijano, 1981, p. 39). 
blos originarios. Una característica específica de este debate fue tener como punto de partida el examen de estas prácticas emancipadoras que están levantando un horizonte histórico de sentido alternativo:

Bien vivir, para ser una realización histórica efectiva, no puede ser sino un complejo de prácticas sociales orientadas a la producción y a la reproducción democráticas de una sociedad democrática, un otro modo de existencia social, con su propio y específico horizonte histórico de sentido, radicalmente alternativos a la colonialidad global del poder y a la colonialidad/modernidad/eurocentrada (Quijano, 2014, p. 847).

Se trata, en consecuencia, de una racionalidad diferente a la racionalidad instrumental eurocéntrica que se encuentra en la base de la organización de los diferentes ámbitos de las relaciones sociales: la solidaridad entre los seres humanos y la armonía entre los seres humanos con la naturaleza. Este proyecto implica la descolonialidad del poder y constituye una alternativa al patrón de poder colonial/moderno, y como señalaba Mariátegui, ${ }^{5}$ se trata de recuperar las raíces indígenas del futuro. Además, este proyecto cuestiona el patrón científico-tecnológico dominante que tiene como base la idea de progreso inevitable. Las luchas y experiencias descoloniales que se encuentra en la base del emergente horizonte histórico de futuro se caracterizan por su carácter no coyuntural, porque sus luchas son políticas y epistémicas y porque establecen espacios autónomos de autogobierno.

No se trata de un proyecto utópico. Estamos viviendo un periodo histórico de transición caótico. Se trata, por lo tanto, de un sistema histórico complejo extremadamente inestable, en donde pequeñas modificaciones pueden producir grandes transformaciones. ${ }^{6} \mathrm{La}$ "sensibilidad a las condiciones iniciales" de un nuevo orden social que se encuentra en el proceso del bien vivir puede convertirse en el núcleo central la descolonialidad de las relaciones de poder que se establecieron con la conquista europea de lo que sería América: la igualdad en las relaciones de género, la reciprocidad en las relaciones de trabajo, el au-

5 "El pasado incaico — escribió Mariátegui en el artículo "La tradición nacional”- ha entrado en nuestra historia, reivindicado no por los tradicionalistas sino por los revolucionarios. En esto consiste la derrota del colonialismo [...]. La revolución ha reivindicado nuestra más antigua tradición” (Mariátegui, 1994, t. I, p. 326).

6 En los sistemas dinámicos, como sostiene Ilya Prigogine (2001, p. 32), "los sistemas caóticos son un ejemplo extremo de sistema inestable: en ellos las trayectorias correspondientes a las condiciones iniciales tan vecinas como se quiera divergen de manera exponencial en el curso del tiempo. Entonces hablamos de 'sensibilidad a las condiciones iniciales', y lo ilustramos con la conocida parábola del 'efecto mariposa' que dice que el aleteo de una mariposa en la cuenca amazónica puede afectar el clima de Estados Unidos”. 
togobierno en las relaciones de autoridad, la interculturalidad —o diálogo de saberes- en las relaciones intersubjetivas y que los seres humanos sepamos estar atentos a una "escucha poética" de la naturaleza, que es una realidad viva y no un mundo silencioso y monótono, como lo han señalado con bastante perspicacia Ilya Prigogine e Isabelle Stengers (2004, p. 325), refiriéndose a la nueva alianza entre la ciencia y el mundo natural.

En conclusión, se ha querido abrir aquí los lineamientos generales del debate de tres cuestiones que son fundamentales en la obra de Aníbal Quijano. Quedan pendientes, en la perspectiva de continuar la discusión sobre la colonialidad/descolonialidad del poder, la exploración de dos problemáticas estrechamente relacionadas: por un lado, el examen de las relaciones y rupturas con otros enfoques teóricos vinculados a la descolonización, como es el caso de los estudios poscoloniales con los que se le busca emparentar; por otro lado, la necesidad de realizar estudios de ámbitos específicos de la realidad histórico-social desde esta perspectiva teórica y epistemológica que permita ampliar el conocimiento del mundo y la exigencia moral de su transformación. 


\section{Bibliografía}

Escobar, A. (2003). Mundos y conocimientos de otro modo. El programa de investigación de modernidad/colonialidad latinoamericano. Tabula Rasa, 1, 51-86.

Mariátegui, J. C. (1994). Mariátegui total (dos tomos). Lima: Amauta.

Marx, K. (1972). Elementos fundamentales para la crítica de la economía política 18571858 (tomo 2). México D. F.: Siglo XXI Editores.

Mignolo, W. (2003). Historias locales/diseños globales. Colonialidad, conocimientos subalternos y pensamiento fronterizo. Madrid: Akal.

Prigogine, I. (2001). El fin de las certidumbres. Madrid: Taurus.

Prigogine, I. y Stengers, I. (2004). La nueva alianza. La metamorfosis de la ciencia. Madrid: Alianza Editorial.

Quijano, A. (2014). Cuestiones y horizontes: de la dependencia histórico-estructural a la colonialidad/descolonialidad del poder. Buenos Aires: CLACSO.

Quijano, A. (2013). El moderno Estado-nación en América Latina: cuestiones pendientes. Yuyaykusun, 6, 15-28.

Quijano, A. (2009). La crisis del horizonte de sentido colonial/moderno/eurocentrado. En Mejía, J. (Ed.). Sociedad, cultura y cambio en América Latina. Lima: Universidad Ricardo Palma.

Quijano, A. (2007). Don Quijote y los molinos de viento en América Latina. Investigaciones Sociales, $X(16), 347-368$.

Quijano, A. (2004). O “movimento indígena” e as quetoes pendentes na America Latina. Política Externa, 12(4), 77-97.

Quijano, A. (2003). Notas sobre "raza" y democracia en los países andinos. Revista Venezolana de Economía y Ciencias Sociales, 9(1), 53-59.

Quijano, A. (2001). Colonialidad, poder, cultura y conocimiento en América Latina. En Mignolo, W. (Comp.). Capitalismo y geopolítica del conocimiento. El eurocentrismo y la filosofía de la liberación en el debate intelectual contemporáneo (pp. 117-131). Buenos Aires: Signo.

Quijano, A. (2000a). Colonialidad del poder y clasificación social. Journal of WorldSystems Research, VI(2), 342-386.

Quijano, A. (2000b). Colonialidad del poder, eurocentrismo y América Latina. En Lander, E. (Comp.). Colonialidad del saber: eurocentrismo y ciencias sociales. Perspectivas latinoamericanas (pp. 201-246). Buenos Aires: CLACSO, UNESCO.

Quijano, A. (2000c). ¡Qué tal raza! Revista Venezolana de Economía y Ciencias Sociales, 6(1), pp. 37-45. 
Quijano, A. (2000d). Colonialidad del poder, globalización y democracia. Tendencias Básicas de Nuestra Época, 1, 21-65.

Quijano, A. (1997). Estado-nación, ciudadanía y democracia: cuestiones abiertas. En González, H. y Schmidt, H. (Coord.). Democracia para una nueva sociedad (modelo para armar). Caracas: Nueva Sociedad.

Quijano, A. (1996). Presentación. En Coronado, J. y Pajuelo, R. Villa El Salvador: poder y comunidad. Lima: CECASAM, CEIS.

Quijano, A. (1993). Raza, etnia y nación en Mariátegui: cuestiones abiertas. En Quijano, A. et al. José Carlos Mariátegui y Europa. El otro aspecto del descubrimiento (pp. 167188). Lima: Amauta.

Quijano, A. (1992). Notas sobre a questão da identidade e nação no Peru. Estudos Avançados, 6(16).

Quijano, A. (1991a). La modernidad, el capital y América Latina nacieron en el mismo día (entrevista con Nora Velarde). ILLA. Boletín del Centro de Educación y Cultura, $10,42-57$.

Quijano, A. (1991b). Colonialidad y modernidad/racionalidad. Revista del Instituto Indigenista Peruano, 13(29), 11-20.

Quijano, A. (1990a). Notas sobre los problemas de la investigación social en América Latina. Revista de Sociología, 6(7), 11-26.

Quijano, A. (1990b). La nueva heterogeneidad estructural de América Latina. Hueso Húmero, 26, 8-33.

Quijano, A. (1988). Modernidad, identidad y utopía en América Latina. Lima: Sociedad y Política Ediciones.

Quijano, A. (1975). Imperialismo y clase obrera en América Latina. En Magri, L., Rossanda, R.; Claudín, F. y Quijano, A. Movimiento obrero y acción política. México D. F.: Era.

Quijano, A. y Wallerstein, I. (1992). Americanity as a Concept or the Americas in the Modern World-System. International Journal of Social Sciences, 134, 617-627. 